\title{
0 modelo federativo e o regime de concessão de incentivos fiscais no imposto sobre circulação de mercadoria
}

The federative model and the system of grant tax incentives in the tax movement of goods

\author{
Bruno Vinícius Lima Brigiato ${ }^{1}$ \\ Ĺvia Graziela Pini ${ }^{2}$ \\ Luisa Rotondo Garcia ${ }^{3}$
}

\begin{abstract}
Resumo
0 presente artigo analisa o possível confronto entre o princípio federativo e 0 sistema de concessão de incentivos fiscais em matéria de imposto sobre circulação de mercadoria (ICM). Para tanto, inicialmente discorre sobre as características essenciais do modelo federativo, ressaltando o caráter de cooperação que grava 0 federalismo brasileiro. Examina os principais aspectos do regime de concessão de incentivos no ICM, contrapondo tal sistemática à autonomia dos entes em uma federação. Analisa a relativização de princípios constitucionais, como o da livre concorrência, da diminuição das desigualdades regionais e da autonomia dos entes federados, para ao final concluir que, em nome do bem-estar da coletividade em âmbito nacional, se justifica a relativização de certos princípios para que outros possam ser alcançados.
\end{abstract}

Palavras Chave: Federação; Federalismo de cooperação; Autonomia dos entes federados; Incentivos fiscais; Convênios; Guerra fiscal.

\begin{abstract}
This article examines the possible confrontation between the federal principle and the system of granting tax incentives in the tax on movement of goods (ICM). Thus, initially discusses the essential features of the federal model, emphasizing the character of cooperation that records the Brazilian federalism. It examines key aspects of the system of granting tax incentives in the ICM, contrasting this systematic against the autonomy of the entities from a federation. It also examines the relativization of constitutional principles such as free competition, as the reduction of regional inequalities and as the autonomy of federal entities. In final, it concludes that, in name of the welfare of the community at the national level, it justifies the relativization of certain principles to that others be achieved.
\end{abstract}

Keywords: Federation; Federalism of cooperation; Autonomy of federal entities, Tax incentives; Covenants; War tax.

\footnotetext{
${ }^{1}$ Bacharelando em Direito pela Universidade Estadual de Londrina - UEL

${ }^{2}$ Bacharelando em Direito pela Universidade Estadual de Londrina - UEL

${ }^{3}$ Bacharelando em Direito pela Universidade Estadual de Londrina - UEL
} 


\section{Introdução}

O princípio federativo prega, dentre outras características, a autonomia dos entes federados. Em regra, cabe ao ente político competente para instituir determinado tributo, a concessão de incentivos, benefícios e isenções fiscais em relação a ele.

O imposto sobre circulação de mercadorias exige uma sistemática diferente, tendo em vista que consiste em uma das principais fontes de arrecadação dos Estados-membros, 0 que causa a intenção dos mesmos em atrair cada vez mais contribuintes para sua área de tributação. Para tanto, a Constituição Federal excepcionou a concessão de inventivos fiscais no ICM, exigindo que para sua realização fossem celebrados convênios entre todos os Estados e o Distrito Federal, e que tal incentivo nascesse de um acordo entre todos estes entes.

Surge aí a discussão de que dita exigência de consenso para concessão de incentivo de um imposto de competência estadual não feriria a autonomia dos entes da federação. Nesse sentido, é preciso analisar os princípios que norteiam a Constituição Federal de nosso país, analisando possíveis relativizações dos mesmos.

\section{0 federalismo - noções e questões}

Para se compreender a discussão que cerca o regime de concessão de incentivos fiscais em matéria de ICM , faz-se mister discorrer a respeito do princípio federativo, tão relevante para a análise de assuntos na seara tributária. Corrobora tal entendimento José Eduardo Soares de M elo (2005, p.16), ao afirmar que "a federação constitui uma das pedras fundamentais do edifício jurídico [...], com ampla aplicação no que concerne às normas de imposição tributária".

Nesse sentido, 0 artigo 1 으 da Carta Magna ressalta formar a República Federativa do Brasil a união indissolúvel dos Estados e Municípios e do Distrito Federal, enquanto o artigo 60, §4ํำ prevê que "[...] Não será objeto de deliberação a proposta de emenda tendente a abolir: I - a forma federativa de Estado". Por este motivo, quem realiza a interpretação do direito deve, em seus pensamentos, considerar a Federação em si. Afinal, ela não é algo a ser alcançada, mas se constituir em realidade (CARRAZZA, 2006, P.123). 


\section{0 modelo federativo e o regime de concessão de incentivos fiscais no imposto sobre circulação de mercadoria}

Contrapondo o Estado Unitário, que é "aquele que apresenta uma organização política singular, com um governo único de plena jurisdição nacional, sem divisões internas que não sejam simplesmente de ordem administrativa" (MALUF, 1991, p.165), exsurge 0 Estado Federal, o qual "se divide em províncias politicamente autônomas, possuindo duas fontes paralelas de direito público, uma nacional e outra provincial" (M ALUF, 1991, p.165).

Em que pese a diferenciação explícita da forma de Estado federalista das demais, não chegam os autores em consenso quando versam a respeito da caracterização de seus elementos. Halina Zasztownt Sukiennicks, lembrada por Oswaldo Aranha Bandeira de M ello, afirma:

\footnotetext{
Nenhum Estado se assemelha a outro, de tal forma que se possa dizer que os seus respectivos regimes sejam idênticos. Eles, quando muito, podem ser análogos. Para classificar um organismo estático nos quadros da noção Estado Federal, subsiste a mesma dificuldade. Os Estados que iniciaram o regime federativo, e que serviriam, portanto, de base para a elaboração das diversas teorias sobre a natureza jurídica do Estado Federal, são os únicos que nunca têm contestada a sua estrutura federal. 0 mesmo não se dá com os outros países, pois os regimes, embora modelados sobre os dois primeiros, deles sempre se afastam e, muitas vezes, de maneira importante (MELLO apud CARRAZZA, 2006, p. 125).
}

De acordo com a supra relatada concepção, Maluf (1991, p.167) revela serem quatro características essenciais do federalismo, à luz da forma de Estado federal mais conhecida - a norte-americana: a "distribuição do poder de governo em dois planos harmônicos", quais sejam, um central e outro local, repartidos constitucionalmente, reservada aos Estados-membros a competência residual, com superioridade do governo federal apenas quando tal concorre com os demais componentes da federação; o "sistema judiciarista" de forma presente, possuindo em sua composição um Supremo Tribunal Federal; "Poder Legislativo na composição bicameral”, englobando um Senado formado por representação igualitária de membros dos Estados-membros, e Câmara dos Deputados; e "constância dos princípios fundamentais da Federação e da República", na medida em que a integridade dos aludidos princípios sejam resguardados por intervenção federal, garantias propriamente ditas e rigidez proveniente da Constituição.

Geraldo Ataliba, por usa vez, revela sete características - muitas delas semelhantes às ora apresentadas: 
1.esquema de constituição rígida; 2. um poder constitucional próprio nos Estados; 3. existência de um território próprio; 4 . existência de um povo próprio; 5 . os poderes derivam de sua constituição compatibilizada com a repartição de competências que está na Constituição Federal; 6 . representação proporcional da vontade do povo dos Estados no órgão legislativo da União, além de representação dos Estados, paritariamente nesse órgão; 7. Corte constitucional que assegure a supremacia da Constituição Federal (ATALIBA apud M ELO, 2005, p.16/17)

No contexto federalista apresentado, grande questionamento é constatado sobre a soberania. Esta pode ser definida como "último à autoridade política, significando dizer a não existência de poderes acima do soberano, que então promove a tomada absoluta das suas decisões políticas" (ZIM M ERM ANN, 2006, p. 231/232). A soberania, segundo Carrazza (2006, p.128), é una, já que é exclusiva do Estado; originária, por ter fonte própria; indivisível, desaparecendo se for fragmentada; e inalienável, sendo irrenunciável pelo Estado, mormente em condições que a desvantagem seja explícita.

Como ressaltado, o Estado é a instituição que possui a soberania, utilizando-a para estabelecer relações com demais Estados, de modo igualitário e para se posicionar em grau de superioridade ou antagonismo às demais instituições (CARRAZZA, 2006, p.126). Esta exclusividade do governo federal em relação à detenção do atributo da soberania advém do chamado pacto federativo resultante da exaração da indissolúvel e permanente vontade nacional (M ALUF, 1991, p.168).

Assim, acabam as unidades que compõem a federação perdendo parcela de sua autonomia política em benefício da federação em seu todo. Ocorre que, para isto correr, deve haver expressa previsão e delimitação constitucional. Exige-se tal requisito porque a Carta Magna não é outorgada pelo governo federal, mas promulgada de acordo com os anseios de toda a nação. Na verdade, não há uma limitação dos poderes que detêm os Estados-membros, e sim autolimitação, já que eles participam do processo (M ALUF, 1991, p. 168/169).

Adentrando ao modelo federalista pátrio, detalhado na Constituição Federal, a qual estabelece sua formação pela união indissolúvel dos Estados, Municípios e do Distrito Federal, observa-se, desde já, que três ordens jurídicas coexistem no Brasil, à luz de M elo (2005, p.17): 


\title{
0 modelo federativo e o regime de concessão de incentivos fiscais no imposto sobre circulação de mercadoria
}

A primeira delas é a nacional, exercida pelo Estado federal dotado de soberania, principalmente quando o mesmo pratica a função de representar o país brasileiro em âmbito internacional ou legisla em nível superior àquele dos outros membros da federação.

Desta ordem jurídica emanam as leis nacionais, que, nas palavras do autor, "contém-se na própria Constituição Federal, não só quanto à materialidade, mas também no que atina à impossibilidade jurídica de violarem a autonomia dos entes periféricos, limitando seus poderes tributários". Importante dizer, de igual modo, que as normas nacionais serão resultantes da atuação do Congresso Nacional. 0 poder legislativo federal, além das normas nacionais, edita as normas federais - que se referem a conteúdo cuja regulamentação recai restritamente às atribuições do ente federal.

Complementando a aludida ordem jurídica nacional, há igualmente a central e as regionais - também chamadas de periféricas. Tais configuram-se em ordens parciais, atribuídas à União (central), Estados (regional) e Distrito Federal (regional). Quanto aos Municípios, questionamento sobre sua real participação na Federação brasileira não será abordado, haja vista o tema central do artigo. Sobre as ordens jurídicas expostas, Carrazza diz:

\begin{abstract}
Não padece dúvida de que estas ordens jurídicas possuem campos de atuação perfeitamente traçados pela Lei Máxima, de tal arte que em nenhuma hipótese interferem umas com as outras. Nem, muito menos, atritam. Como, em termos estritamente jurídicos, só podemos falar em hierarquia de normas quando umas extraem de outras a validade e legitimidade (Roberto J. Vernengo), torna-se onipatente que as leis nacionais (do Estado Brasileiro), as leis federais (da União) e as leis estaduais (dos Estados-membros) ocupam o mesmo nível, vale consignar, umas não preferem às outras. Realmente, todas encontram seu fundamento de validade na própria Carta Magna, apresentando campos de atuação exclusivos e muito bem discriminados. Por se acharem igualmente subordinadas à Constituição, as várias ordens jurídicas são isônomas, ao contrário do que proclamam os adeptos das "doutrinas tradicionais (CARRAZA, 2006, p.139).
\end{abstract}

Nesse diapasão, o poder de tributar é repartido entre as diversas pessoas políticas, de acordo com a parcela cedida a cada uma pela Constituição Federal. "O poder de tributar originariamente uno por vontade do povo (Estado Democrático de Direito) é dividido entre as pessoas políticas que formam a federação" (COÊLHO, 2007, p.71). Ademais, as leis nacionais, que devem ser respeitadas por todos os entes, são editadas tanto por leis ordinárias quanto complementares (CARRAZA, 2006, p.139/140). 
Por sua vez, nos diversos atos decisórios dos membros da federação, prudente é que não haja, de modo algum, qualquer ofensa que possa desencadear violação ao princípio federativo, que rege a formação do Estado brasileiro. Geraldo Ataliba (apud CARRAZA, 2006, p.149) coloca que "o princípio federal, em suas mais essenciais exigências, só pode ser revogado por força de uma verdadeira revolução, que deite por terra o Texto Constitucional e ab-rogue categoricamente todo o sistema, a partir de suas bases".

Com base nisso, qualquer norma que fira o pacto federativo deve ser rechaçada. Como afirma Carraza (2006, p.149), "as leis do Congresso Nacional [...] deverão sempre levar em conta a existência dos Estados e de suas competências [...] Os Estados-membros, evidentemente, em nome do princípio federativo, não poderão, de seu turno, invadir as searas federal e nacional". É através do equilíbrio entre União e Estados-membros (e M unicípios) que a federação se mantém em funcionamento.

\section{Federalismo de cooperação}

De outra via, explicita-se que o federalismo enseja que seus membros sejam detentores de igualdade jurídica entre si - o que não significa que dois estados sejam materialmente iguais. Qualquer tratamento diferenciado que exista entre tais só pode lastreado na justificativa de fortalecimento da federação. Surge, por conseguinte, o conceito de federalismo cooperativo:

0 federalismo cooperativo nada mais é do que o resultado [do] equilíbrio federativo, alcançado apenas em termos teóricos, garantidor do desenvolvimento nacional, com a conseqüente redução das desigualdades regionais e cooperação dos entes estatais entre si. Destarte, a palavra básica desse modelo cooperativo é colaboração. Mais uma vez chegamos aqui à conclusão de que uma justa e equitativa distribuição de competências e de receitas é imprescindível ao desenvolvimento do modelo federativo de qualquer país, embora saibamos da dificuldade de se atingir, ao menos, níveis aceitáveis dessa distribuição, tendo-se em vista a existência de interesses pluralistas que afetam o seu resultado (PEREIRA NETO, 2006 . p.)

Por derradeiro, não há irregularidade em tratar Estados-membros desiguais de forma desigual, se assim houver necessidade. Afinal, um dos objetivos da República Federativa do Brasil é garantir justamente o desenvolvimento nacional. Caso seja alcançado, todos os membros da federação serão contemplados com as benesses, pois um Estado- 


\section{0 modelo federativo e o regime de concessão de incentivos fiscais no imposto sobre circulação de mercadoria}

membro que alcance o nível de desenvolvimento de outro só tende a fortificar a união indissolúvel entre estes, Distrito Federal e Municípios.

\section{O sistema de concessão de incentivos fiscais no ICM e a relativização da autonomia dos entes federados}

Seguindo a idéia de autonomia dos entes federados, a qual é retirada da própria essência do modelo federativo, cabe a cada Estado prover suas necessidades sem interferência federal ou de outros Estados-membros. Para tanto, a Constituição Federal conferiu a cada ente a competência para instituir, arrecadar e regular os tributos a ele destinados (CARRAZZA, 2006).

Embora a concessão de isenções e de outros incentivos tributários seja feita, em regra, por meio de lei ordinária, e emane da mesma pessoa política competente para criar o tributo, a isenção em sede de ICM é concedida de forma diferente.

Como se sabe, o artigo 155 da Constituição Federal preceitua que "compete aos Estados e ao Distrito Federal instituir impostos sobre: [...] II - operações relativas à circulação de mercadorias [...], ainda que as operações [...] se iniciem no exterior".

A peculiaridade dos incentivos fiscais no imposto sobre circulação de mercadoria advém do fato de nem os Estados, nem o Distrito Federal, poderem concedê-los unilateralmente. Dessa forma preceitua 0 artigo 155, §2º, XII g, da Constituição Federal ao dispor que "cabe à lei complementar [...] regular a forma como, mediante deliberação dos Estados e do Distrito Federal, isenções, incentivos e benefícios fiscais serão concedidos ou revogados".

Referida "deliberação" já existia antes do advento da Constituição Federal de 1988, tendo em vista que a Lei Complementar no 24, de 7 de janeiro de 1975, já concretizava esse procedimento através do instituto dos convênios.

Os convênios exigidos para a concessão de incentivos fiscais em matéria de ICM são celebrados, segundo o próprio texto constitucional, entre os Estados e o Distrito Federal, de forma que a efetiva concessão dos mesmos depende de acordo entre todos os entes participantes.

Os incentivos e benefícios fiscais são situações desonerativas de gravames tributários, concedidos pelo Poder Público, com o fim de estimular determinadas atitudes dos contribuintes, de modo que haja repercussão na seara de interesse público que se pretende atingir. Pode-se falar, assim, em verdadeira atuação no campo da extrafiscalidade, tendo em vista que os 
instrumentos tributários são utilizados para fins não-fiscais, e não como mera fonte de arrecadação (MELO, 2004).

Tendo em vista que o Estado abre mão de parte do valor a ser arrecadado, objetivando o desenvolvimento do bem-estar social, tal evolução deve ser visada em um âmbito nacional. De fato, como já exposto ao se tratar do sistema federativo, o modelo federal brasileiro é baseado na cooperação, com a decorrência de que qualquer tratamento diferenciado entre os entes políticos só pode ser empregado sob a justificativa de fortalecimento da federação como um todo.

Assim, ao se ter o princípio da redução das desigualdades regionais como um dos principais pilares do sistema de concessão de incentivos fiscais, é justificada a exigência de consenso entre os entes federados nos convênios firmados.

Vislumbrando-se que, caso aos Estados fosse permitida a concessão de incentivos a seu bel-prazer, a livre concorrência entre os mesmos tomaria imensas proporções, acarretando uma verdadeira guerra fiscal entre tais entes, fazendo surgir, assim, a importância da existência dos convênios.

Conforme entendimento exposto pelo Conselho Administrativo de Defesa Econômica, órgão do M inistério da Justiça, a respeito da nocividade da guerra fiscal:

Princípios constitucionais da livre concorrência e da promoção do bem-estar devem ser compatibilizados com outros princípios, como o da redução das desigualdades regionais, de forma que um deles possa ser relativizado [...] para assegurar a realização de outro (Consulta no 38/99 - Rel. Conselheiro Marcelo Calliati - j. 22.03.2000 - DOU 1-E de 28.04, 2000, p.1 apud M ELO, 2004, p. 278).

Por todo o exposto, e pelo impacto que incentivos desmotivados poderiam causar no bem-estar da coletividade, as normas constitucionais que exigem pleno acordo entre os Estados em matéria de ICM são verdadeiras limitações a autonomia destes entes, sendo, porém, vedado que tal autonomia seja alegada quando o interesse buscado é o bem-estar da nação.

\section{0 desrespeito à exigência de convênio para concessão de incentivos no ICM}

Como observado pelo Conselho Administrativo de Defesa Econômica, no documento já mencionado: 


\section{0 modelo federativo e o regime de concessão de incentivos fiscais no imposto sobre circulação de mercadoria}

O simples cumprimento da legislação sobre a concessão de incentivos fiscais realizaria a necessária compatibilização entre os princípios constitucionais [...], permitindo a relativização pontual do princípio da livre concorrência apenas naqueles casos em que se avança o princípio da redução das desigualdades, na medida adequada, de maneira a trazer benefícios líquidos para a coletividade (Consulta no 38/99 - Rel. Conselheiro Marcelo Calliati - j. 22.03.2000 - DOU 1-E de 28.04, 2000, p.1 apud M ELO, 2004, p. 279).

Ocorre que, embora se trate de norma constitucional que restrinja a concessão de incentivos fiscais à forma de convênio, "unilateralmente, as unidades federativas têm expedido leis, decretos e atos administrativos, outorgando vantagens fiscais, financeiras, creditícias e operacionais, que afetam a carga impositiva" (MELO, 2004, p. 274).

Como conseqüência de tal desrespeito a exigências legais, os Tribunais Superiores vêm adotando severas posições no combate à "guerra fiscal" entre os entes, consolidando entendimento no sentido de que padece de inconstitucionalidade qualquer incentivo fiscal do ICM que seja concedido sem previsão em convênio.

Assim, aos Estados prejudicados resta recorrer ao Poder Judiciário, pleiteando a inconstitucionalidade dos incentivos concedidos unilateralmente, fazendo cumprir a lei que foi idealizada para benefício do país como um todo.

\section{Conclusão}

0 princípio federativo encontra-se esculpido na própria Constituição Federal, do qual se extrai, dentre outras características, que "a organização político-administrativa da República Federativa do Brasil compreende a União, os Estados, o Distrito Federal e os Municípios, todos autônomos, nos termos desta Constituição" (C.F. 1989, artigo 18, grifo nosso).

Contudo, 0 artigo 30 da Carta Magna elenca, dentre os objetivos fundamentais da República Federativa do Brasil, a redução das desigualdades regionais.

Salta aos olhos em nosso país a diferença do nível de desenvolvimento das regiões que o compõem. É fato que determinadas regiões recebem menos investimentos da iniciativa privada do que outras.

Um dos instrumentos vislumbrados pelos Estados-membros para atrair tais investimentos é a concessão de isenções, incentivos e benefícios fiscais relativos ao imposto sobre circulação de mercadoria (ICM ). 
Caso não houvesse limitações a essa faculdade de conceder incentivos fiscais à iniciativa privada pelos Estados, estes acabariam deflagrando uma "guerra fiscal" entre os mesmos, acarretando vantagens para uma parcela, porém prejuízos para a outra e para a nação como um todo, evidentemente.

Vislumbrando tal situação, a Constituição Federal determinou que, em sede de imposto sobre circulação de mercadoria, isenções, benefícios e incentivos fiscais só poderiam ser concedidos mediante deliberação entre os Estados e o Distrito Federal.

Para tanto, a Lei Complementar no 24 de 1975 traz a figura dos convênios, concretizando tal "deliberação" prevista pela norma constitucional. Dessa forma, incentivos fiscais só poderão ser concedidos após aprovação por todos os entes participantes dos convênios, ou seja, todos os Estados e o Distrito Federal.

Assim se pretendeu evitar a tão temida "guerra fiscal", além de coibir o maior crescimento de regiões do país já desenvolvidas, em detrimento do desenvolvimento de outras.

A princípio, a exigência de convênio para deliberar sobre uma matéria que, em regra, poderia ser determinada isoladamente por cada Estado, constitui afronta à autonomia dos entes federados constitucionalmente prevista.

Contudo, justamente pelo fato de dita limitação à autonomia visar ao alcance de um objetivo fundamental de nossa Federação, os limites a essa autonomia se tornam legítimos. Dessa forma, são relativizados determinados princípios em nome da concretização de outros constitucionalmente elencados, principalmente, o objetivo da redução das desigualdades regionais.

Embora a simples obediência à norma legal já fosse suficiente para coibir a "guerra fiscal", os Estados ignoram as exigências constitucionais e, instigados pela obtenção de mais investimentos e conseqüente arrecadação significativamente maior, permanecem na concessão isolada dos incentivos fiscais relativos ao imposto sobre circulação de mercadoria.

Resta, assim, ao Poder Judiciário, prolatar decisões rigorosas coibindo tal prática, na esperança de que os Estados que agem irregularmente percebam a prevalência do interesse da coletividade sobre interesses meramente regionais. 


\section{0 modelo federativo e o regime de concessão de incentivos fiscais no imposto sobre circulação de mercadoria}

\section{Referências}

CARRAZZA, Roque Antônio. Curso de Direito Constitucional Tributário. 22. Ed. São Paulo: Malheiros, 2006.

COÊLHO, Sacha Calmon Navarro. Curso de Direito Tributário Brasileiro. 9.ed. Rio de Janeiro: Forense, 2007.

M ALUF, Sahid. Teoria Geral do Estado. 21. Ed. São Paulo: Saraiva, 1991.

M ELO, José Eduardo Soares de. ICM S: teoria e prática. 7. ed. São Paulo: Dialética, 2004.

M ELO, José Eduardo Soares de. Curso de Direito Tributário. 6. ed. São Paulo: Dialética, 2005.

PEREIRA NETO, Luiz Gonzaga. A Teoria da Federação e o Estado Federal Brasileiro. Disponível em: <http://www.escola.agu.gov.br/revista/Ano_VI_junho_2006/LGonzaga-

Federalismo.pdf>. Acesso em 09 de novembro de 2008.

ZIM M ERM ANN, Augusto. Curso de Direito Constitucional. 4. Ed. Rio de Janeiro: Lúmen luris, 2006. 